\title{
Research on the Reform of Applied College Teaching Based on the Mixed Teaching Mode of "MOOC Plus Flipped Class"*
}

\author{
Lili Qi \\ School of Economics and Management \\ Heihe University \\ Heihe, China 164300
}

\author{
Hui Xie \\ School of Economics and Management \\ Heihe University \\ Heihe, China 164300
}

\begin{abstract}
MOOC teaching mode is an important trend in the development of higher education. In the teaching process of many colleges and universities, it is also gradually applied in the classroom teaching process. This teaching mode belongs to the new teaching mode, and there are big problems in the teaching practice. Some students lack initiative in the learning process, which will cause difficulty to break through the practical value of new teaching mode. MOOC, also called Muke in Chinese, is a teaching mode refers to open teaching, large scale and plenty teaching resources, which can effectively adapt to the current development of teaching situation. This mode is developing rapidly in the field of education in China. How to integrate MOOC and flipped class effectively in teaching is an important task to carry out the mixed teaching mode to reform the teaching of application-oriented colleges and universities. At present, teachers should comprehensively reform and innovate the teaching environment of applicationoriented colleges and universities.
\end{abstract}

Keywords-MOOC plus flipped class; mixed teaching; college teaching; reform

\section{INTRODUCTION}

In the long-term development of education, most teachers occupy a dominant position in classroom teaching. In the process of teaching, they instill knowledge in one way, lack independent thinking, lack of exploration ability and knowledge application ability. Therefore, it is necessary to pay attention to the overall reform of classroom teaching mode, actively mobilize students' participation in learning, cultivate students' independent thinking ability, and strengthen students' knowledge understanding ability. In recent years, MOOC and flipped class teaching mode have been sought after by teachers and students in the field of education at home and abroad, and their advanced teaching ideas have a great impact on the traditional teaching mode. MOOC and flipped class have a high degree of complementarity, identity and coupling. The integration of

*Fund: This paper is the key project of 2018 higher education reform research in Heilongiiang Province, and part of the results of the research on the reform of blended teaching mode in application-oriented universities from the perspective of "Massive Open Online Courses" (MOOC) (Project No.: SJGZ20180041). the two teaching modes can give full play to their complementary advantages and improve teaching effectiveness.

\section{THE OVERALL TEACHING IDEA DESIGN OF "MOOC Plus FlipPED Class" MiXEd TEACHING}

At present, it plays an important role in carrying out the mixed teaching mode of "MOOC flip classroom" in an allround way, which can give full play to the application value of the two models in the teaching field, integrate the online MOOC platform and the offline flip classroom teaching mode, reconstruct the traditional classroom mode from the aspects of educational mode, learning mode, teaching activity organization, evaluation mode and so on, can effectively establish a knowledge transfer model with student as the main body and student pull as the guide, and realize the goal of talent cultivation and problem solving. In the course of designing the teaching thought, the mixed teaching of "MOOC flipped class" can transform the teacher's traditional authority status in an all-round way, realize the change of standard knowledge to interactive enlightening teaching mode, and make clear the core teaching goal of students' main body and ability cultivation. In the design of teaching concept, students' interest should be taken as the basic guidance, comprehensive ability cultivation as the core, and the knowledge-oriented mixed instruction design idea. Among them, "giving priority to students" is to give full play to students' learning subject status, weaken teachers' authority status in knowledge teaching, actively build an equal and harmonious communication environment between teachers and students, comprehensively stimulate students knowledge exploration and application ability in teacher guidance, and guide students' self-management and selforganization in learning process. Gradually generate learning processes such as interest attraction, life perspective, task driven, scientific exploration, etc., and pay attention to the application of various information software and hardware tools. For example, Wechat, smart phones, etc., strengthen the distance between teaching and students from the perspective of technology, so as to make online and offline teaching participation more convenient and diversified. In the process of teaching, the core purpose is to ensure the 
screen questions during the video viewing process, and continue the video learning by answering all kinds of questions. Without going back to study again, in the process of setting breakthrough problems, a comprehensive survey of knowledge points can be carried out, and the transfer of knowledge points can be examined. The students can strengthen the understanding and memory of knowledge points through breakthrough stages in the process of learning. Secondly, the MOOC platform interactive forum can put forward open topics, guide students to think independently and explore, and learn through exchange of views and literature review. In the same question, according to the students' thinking direction, it is required to put forward corresponding questions to guide students to think deeply. Finally, through various social platforms and activity forums for students to answer questions and solve doubts, so that students in the self-study stage can feedback on various difficult problems, and timely eliminate learning pressure. Teachers should analyze the common problems and regulate the teaching content. To realize flipped teaching in an allround way, two foundations should be emphasized. First of all, it is necessary to provide motivation for students' followup knowledge teaching in self-study before class. Secondly, the internalization of classroom knowledge can improve the teaching effect and supplement the motivation for students' knowledge construction. students in the course is relatively low. In the process of teaching method implementation, students' basic knowledge is mainly digested and absorbed through daily exercises. The relevant research group can be concluded from practice that in the pre class teaching stage, the teacher's guidance is insufficient, and the ability to understand and accept the key points of knowledge is insufficient through the students' unilateral viewing of videos and exercises, which is difficult to provide the basis for the ability to master and answer the following knowledge. Therefore, in the current mixed teaching mode, teachers should give full play to MOOC online learning platform for interaction, and set multiple interaction modes in the teaching of teachers and students to enrich students' knowledge internalization path. The mode of MOOC online learning stage is to explain doubts and guide divergent thinking.

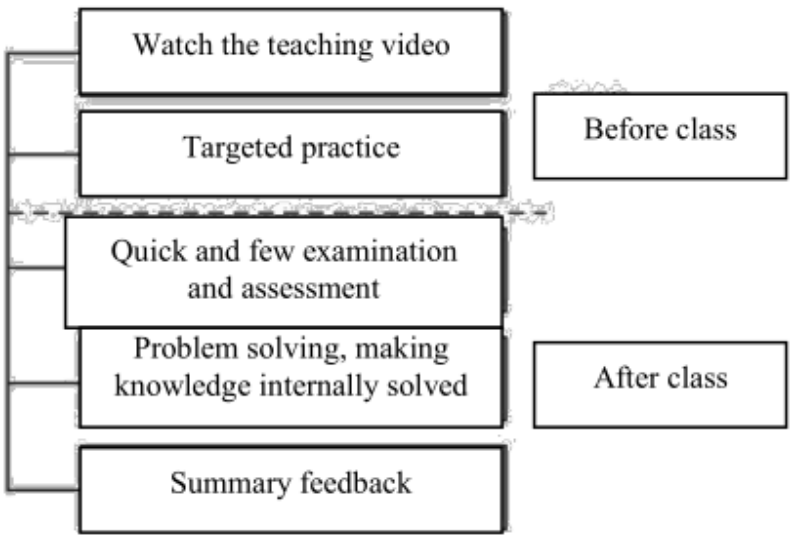

Fig. 1. Robert Talbert's two-stage flipped class teaching model.

First of all, set the breakthrough mission point in the MOOC video, and students can reply according to the bullet

\section{B. Knowledge Internalization and Inquiry Guidance are the Main Teaching Methods in the Process of Project Promotion}

In the first stage of basic knowledge and thinking divergent training, many students can initially establish a learning knowledge map, and can solve many problems on their own. After that, by setting various theme project tasks to drive the students to internalize and apply the knowledge they have learned, they can make a comprehensive transformation from the perspective of rational perception to practical experience. In this process, most students only conduct activities with students through their teacher's identity, and guide teaching methods reasonably through supplementary theme projects, so that each group can master more perfect problem exploration methods and directions. Through the acquisition of all kinds of literature and supplementary practical measures to complete the task of topic exploration, can produce the corresponding project results. Through the theme task form to promote students' exploration in an all-round way, teachers will not interfere with students' specific exploration process in providing corresponding exploration methods and paths, which can strengthen the independence of the exploration process in an all-round way and ensure that the exploration process can always be in the direction of scientific development.

\section{Knowledge Construction as the Main Teaching Mode in the Flipped Class Teaching Stage}

Knowledge construction is mainly the activity of comprehensively combing the existing knowledge and establishing more new knowledge. Before the implementation of the offline flipped class, students have a 
comprehensive grasp of the thematic knowledge through MOOC online learning and thematic project exploration. On this basis, teachers can comprehensively guide students to sort out all existing knowledge through offline flipped class teaching. According to the depth of students' knowledge and the collision of ideological level, more new ideas are produced. In flipped class teaching, teachers are the main constructors of all kinds of knowledge. In the learning achievement sharing of each learning group, the knowledge system is constructed twice by means of view combing, knowledge supplement and comprehensive evaluation of achievements, so as to fundamentally improve the selfconstructed knowledge system ("Fig. 2").

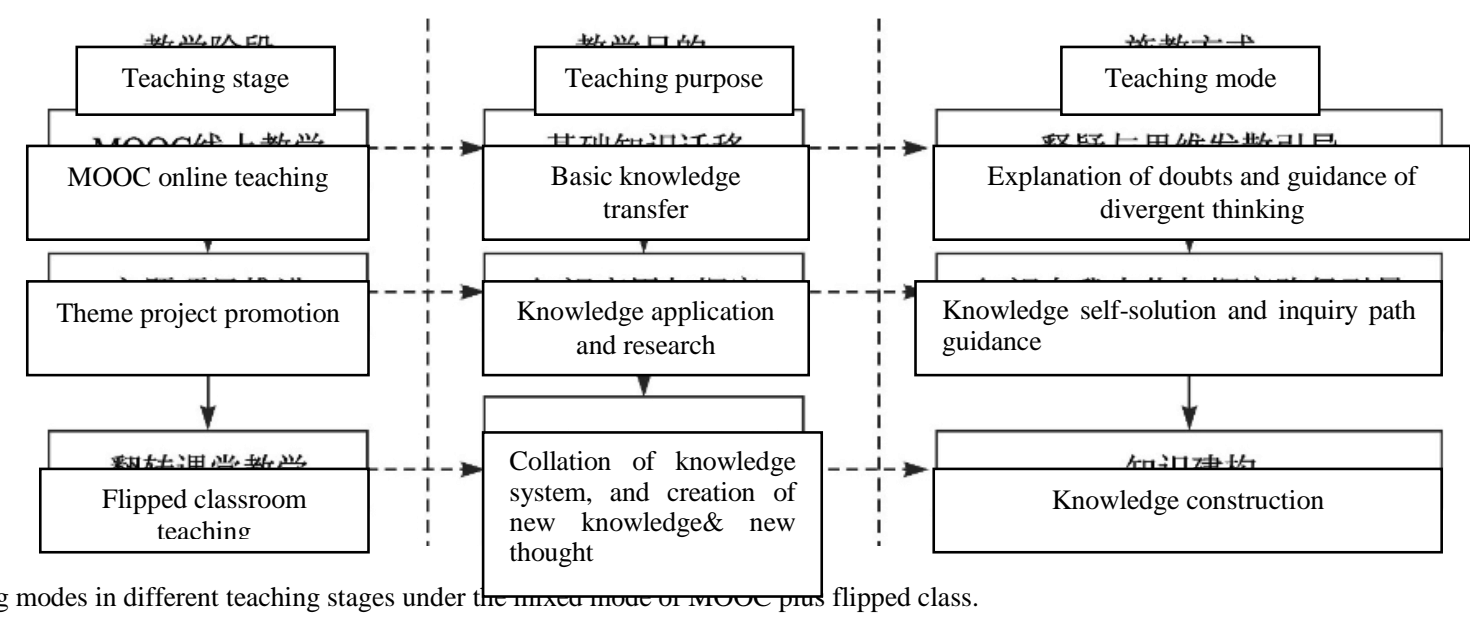

\section{Taking the Teaching Reform and Practice of "Introduction to Computer" as an Example}

In the background of MOOC, it is mainly to design MOOC video alternative mode, self-made knowledge point small video mode and self-secondary development mode. In the secondary development mode, combining with various levels and requirements of various courses, it is necessary to carry out characteristic transformation of MOOC curriculum quality resources, cooperate closely with MOOC curriculum development department, university management department and teachers, and purchase more excellent MOOC curriculum resources in an all-round way. Teachers and teaching management departments should analyze the learning characteristics of students and make secondary development and application of teaching resources; or jointly develop with the developers, and make micro video teaching resources with the professional characteristics of their school. In the overall implementation of flipped class teaching process, it is of great significance to make flipped class teaching resources, among them, it is necessary to pay attention to the overall planning of classroom teaching activities to promote students to internalize a number of knowledge. In the teaching process, teachers should guide students to watch the MOOC course micro video, and then carry out various trainings to complete various new knowledge learning. Teachers can learn and communicate with students through social tools to master various problems in the online learning process. Students internalize all kinds of knowledge in an all-round way through teachers organizing all kinds of offline classroom teaching activities.

It is indispensable to take MOOC as a breadth learning, comprehensively construct offline classroom teaching complementary to $\mathrm{MOOC}+$ characteristic teaching resource courses, among them, including the establishment of computer introduction, the characteristic MOOC course guided by computational thinking. In the process of MOOC curriculum resource sharing, complementary experimental course resources are carried out through the python expansion algorithm and corresponding programming training. The MOOC course section is also carefully created. In the flipped class teaching, it is necessary to carry out discussion teaching, problem teaching and teaching content setting, which is mainly to establish high quality classroom teaching resources consistent with the flipped class teaching objectives, which can be directly applied in the flipped class online teaching. In the application of curriculum resources, the secondary development is selected for application. In the teaching scope of this major, the flipped class teaching is reformed in an all-round way, the teaching video is carried out, the teaching method is effectively combined with the students' learning effect, and the computer thinking teaching is completed in the limited teaching time.

\section{CONCLUSION}

To sum up, the application of the mixed teaching mode of "MOOC plus flipped class" in the course teaching of colleges and universities can comprehensively enhance the students' learning initiative and strengthen the teaching results. In the future teaching activities in colleges and universities, it is necessary to strengthen the construction of teaching resources for students of different levels, carry out comprehensive reform of college courses, and provide sufficient power for the reform and development of application-oriented colleges and universities.

\section{REFERENCES}

[1] Wang Yanbing. Teaching Reform and Practice Exploration of Application-oriented College \& Universities Under the Mixed Teaching Mode of MOOC + flipped class [J]. Shanxi Youth, 2019 (9): 270. (in Chinese) 
[2] Tu Jie. Reform and Practice of Applied College \& University Teaching Under the Mixed Teaching Mode of "MOOC + flipped class" [J]. Art and Science \& Technology, 2019,32 (8): 217. (in Chinese)

[3] You Xiaoming, Fang Zhijun, Yao Xinghua. Teaching Reform and Practice in Application-oriented College \& Universities Under MOOC + flipped class Hybrid Teaching Mode [J]. Software Guide · Educational Technology, 2017, 16 (1): 7-9. (in Chinese)

[4] You Xiaoming, Fang Zhijun, Yao Xinghua. Teaching Reform and Practice in Application-oriented Colleges \& Universities Under MOOC + flipped class Hybrid Teaching Mode [J]. Software Guide (Educational Technology), 2017(001):7-9. (in Chinese)

[5] Li Yan. Teaching Reform and Practice of Application-oriented Colleges \& Universities Under the Mixed Teaching Mode of "MOOC + flipped class" - Taking Architecture Major of Universities as an Example [J]. Heilongjiang Science, 2017,8 (5): 18-19. (in Chinese)

[6] Lei Junbo. A Study on the flipped class Teaching Mode of College English Based on MOOC [J]. Journal of Heilongjiang Institute of Education, 2019, 38 (8): 139-141. (in Chinese)

[7] Du Kun. C Programming Hybrid Teaching Based on "MOOC + flipped class", Design Mixed Teaching [J]. Software, 2019,40 (8): 212-215

[8] Yan Chunyan, Research on the Learning Evaluation Index System of "MOOC + flipped class" Based on AHP [J]. E-commerce, 2018 (12): 77-78,85. (in Chinese)

[9] Zhu Dan. MOOC + flipped class Mixed Teaching Mode Design [J]. Journal of Hebei Agricultural University (Agricultural and Forestry Education Edition), 2018,20 (1): 35-39. (in Chinese) 